\title{
The Effects of Power Levels/Time Periods for Sputtering Cobalt onto Carbon Nanotubes/Graphene Composites and Cobalt Annealed on the Characteristics of Anode Materials for Lithium-Ion Batteries
}

\author{
Chuen-Chang Lin ${ }^{D},{ }^{1}$ You-Lun Shen, ${ }^{2}$ and An-Na $\mathrm{Wu}^{1}$ \\ ${ }^{1}$ Department of Chemical \& Materials Engineering, National Yunlin University of Science and Technology, \\ 123 University Road Sec. 3, Douliu, Yunlin 64002, Taiwan \\ ${ }^{2}$ Dalin Plant, Refining Business Div., CPC Corporation, 50 Yanhai 4th Rd., Siaogang Dist., Kaohsiung 81261, Taiwan \\ Correspondence should be addressed to Chuen-Chang Lin; linchuen@yuntech.edu.tw
}

Received 24 April 2018; Accepted 27 August 2018; Published 16 October 2018

Academic Editor: Zhengping Zhou

Copyright (c) 2018 Chuen-Chang Lin et al. This is an open access article distributed under the Creative Commons Attribution License, which permits unrestricted use, distribution, and reproduction in any medium, provided the original work is properly cited.

\begin{abstract}
Carbon nanotubes/graphene composites are directly grown on nickel foil without additional catalysts by chemical vapor deposition (CVD). Next, the cobalt is deposited on carbon nanotubes/graphene composites by radio frequency (RF) sputtering with different power levels and time periods. Then, the cobalt is transformed into cobalt oxide by annealing. A longer time period of sputtering leads to higher specific capacity. Furthermore, the electrochemical stability of cobalt oxide/carbon nanotubes/graphene composites is higher than that of cobalt oxide.
\end{abstract}

\section{Introduction}

The applications of lithium-ion batteries include portable electronic devices, electric vehicles, and hybrid electric vehicles. Lithium-ion batteries compared to other batteries (such as Ni-Cd, lead-acid, and Ni-MH) possess higher energy densities $\left(100-150 \mathrm{Wh} \mathrm{kg}^{-1}\right)$, higher voltage, and lower maintenance [1]. The energy density and performance of lithium-ion batteries mainly depend on the properties of anode and cathode materials. In this research, we focused on anode materials of lithium-ion batteries.

Wang et al. [2] have reported that hybrid carbon nanotubes (CNTs) and graphene nanostructures applied in lithium-ion batteries were directly grown by ambient pressure CVD; methane was introduced to form graphene on copper foils at $950^{\circ} \mathrm{C}$, and then Fe catalysts were deposited on graphene/copper foils by e-beam evaporation, and ethylene was next introduced to grow pillar CNTs on graphene/ copper foil at $750^{\circ} \mathrm{C}$. Wang et al. [3] also demonstrated that to increase the accessible specific surface area and the stability as well as conductivity between the carbon nanotube bundles and the nickel foam, three-dimensional few layer graphene/multiwalled carbon nanotube architectures were fabricated on oxygen plasma-treated nickel foam coated with Fe catalysts by e-beam evaporation through a one-step ambient pressure CVD process using a mixture of acetylene and hydrogen. In our previous study [4], to control the packing density of CNTs and the number of graphene layers, carbon nanotube/graphene composites were directly grown on cobalt catalyst-coated nickel foam by one-step CVD at different temperatures and times.

Han et al. [5] reported that a cobalt oxide-modified porous carbon was synthesized via a solvothermal method followed by a simple thermal treatment process and its high electrochemical performances (enhanced reversible capacity, excellent cyclic stability, high Coulomb efficiency, and good rate capability) were attributed to the interconnection networks of electrically conductive porous carbon and cobalt oxide nanoparticles, which could provide accessible route for electrolyte diffusion as well as intercalation of $\mathrm{Li}$ ions into the active sites, efficiently prevent volume expansion/ contraction of cobalt oxide during discharge/charge process, 


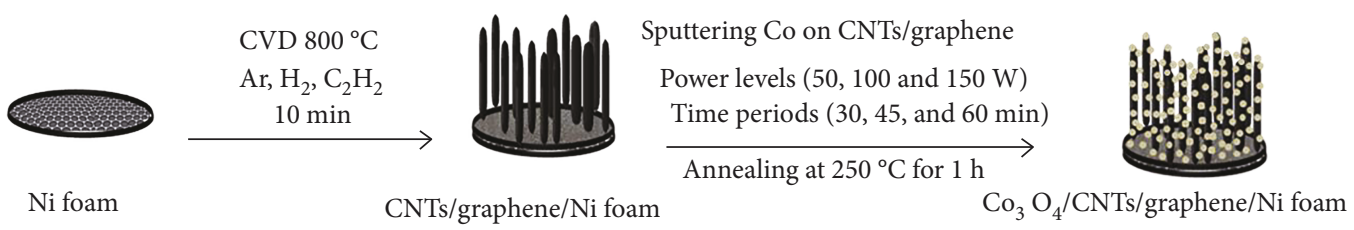

FIGURE 1: Schematic illustration of the fabrication process of $\mathrm{Co}_{3} \mathrm{O}_{4} / \mathrm{CNTs} /$ graphene composites.

and decrease its inner resistance. Yoon and Park [6] demonstrated that a CNTs/cobalt oxide-blended anode was prepared by cobalt oxide nanoparticles and CNTs mixed with Super $\mathrm{P}$ as conductive carbon and poly-vinylidene fluoride (PVDF) as a binder; its cyclic ability and rate capability in comparison with a cobalt oxide anode were probably improved by the high electronic conductivity and mechanical flexibility of CNTs, respectively. Abbas et al. [7] also reported that mesoporous $\mathrm{Co}_{3} \mathrm{O}_{4}$ nanoparticles anchored on CNTs by a chemical coprecipitation method exhibited high capacity as well as rate capability and good capacity retention due to the intimate interaction between the CNTs and $\mathrm{Co}_{3} \mathrm{O}_{4}$ nanoparticles. Li et al. [8] have demonstrated that cobalt oxide/graphene nanostructured composites were prepared by cobalt oxide nanoparticles homogeneously dispersed onto graphene sheets through a chemical deposition method and possessed large reversible capacity in the initial cycle and excellent cyclic stability due to improving the structure stability by the interactions between high conductive graphene sheets and cobalt oxide nanoparticles anchored on the graphene sheets. Wang et al. [9] have reported that cobalt oxide/graphene nanocomposites synthesized by an in situ solution-based method exhibited initial reversible lithium storage capacity and the high conductive graphene was used as a buffer medium to allow volume expansion/contraction of cobalt oxide reacted with lithium by lithium-ion insertion/extraction. Qiu et al. [10] also demonstrated that mesoporous cobalt oxide/graphene nanocomposites synthesized by one-step in situ growth of cobalt oxide on a graphene matrix and the volume expansion/contraction of cobalt oxide nanoparticles could be confined by graphene with large sizes to prevent electrode pulverization during the lithium-ion insertion/extraction process. Lou et al. [11] reported that ultrasmall cobalt oxide nanoparticles/reduced graphene oxide nanocomposites were prepared by a facile solutionbased synthesis and exhibited good rate capability, excellent Coulomb efficiency, and high reversible capacity since cobalt oxide was anchored on graphene which provided a high electronic conductivity as well as an elastic buffer medium. Yang et al. [12] demonstrated that binder free 3D hierarchical graphene nanosheets/cobalt oxide fibers composite papers were synthesized by graphene nanosheets deposited onto electrospun cobalt oxide fibers and possessed good rate capability, very high reversible capacity, and excellent cyclic ability due to high electronic conductivity as well as flexible structure of graphene, large electrode/electrolyte contact area, and short path length for lithium transportation. Yang et al. [13] reported that sandwich-like ultrathin cobalt oxide nanosheet/graphene hybrids were prepared by a layer-by-layer self-assembly and low-temperature annealing method; they

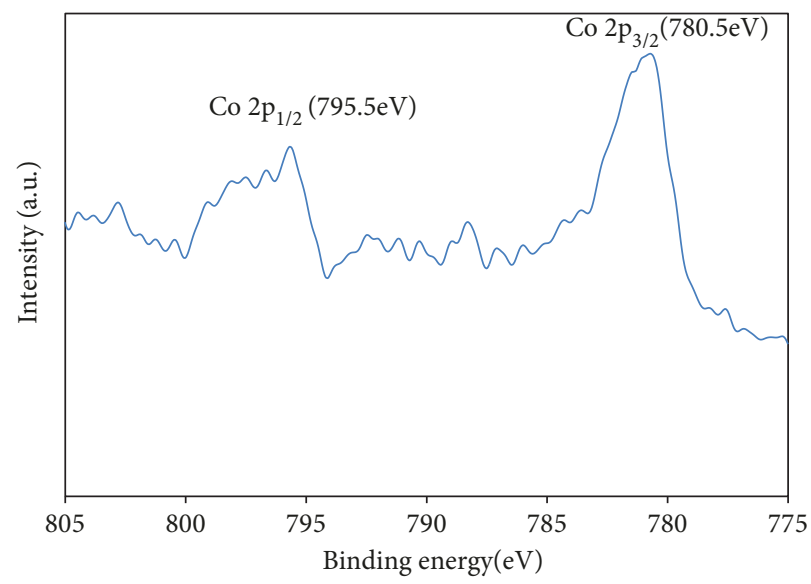

FIGURE 2: XPS spectra in Co $2 \mathrm{p}$ region for cobalt oxide/carbon nanotubes/graphene composites.

possessed very high rate capability and excellent reversible capacity. Wu et al. [14] also reported that $\mathrm{Co}_{3} \mathrm{O}_{4} /$ graphene nanocomposites prepared by solution-phase dispersion of $\mathrm{Co}(\mathrm{OH})_{2}$ on graphene followed transformation of $\mathrm{Co}(\mathrm{OH})_{2}$ into $\mathrm{Co}_{3} \mathrm{O}_{4}$ by annealing treatment exhibited excellent cyclic stability and high rate capability because of graphene being beneficial for allowing large volume expansion of $\mathrm{Co}_{3} \mathrm{O}_{4}$ without the severe cracking or crumbling of electrode materials during discharge/charge cycles. Li et al. [15] have demonstrated that $\mathrm{Co}_{3} \mathrm{O}_{4}$ mesoporous nanostructures directly grown on a graphene membrane by hydrothermal treatment and then annealing possessed excellent capacity retention due to mesoporous nanostructures with enough space being beneficial to strain buffer of $\mathrm{Co}_{3} \mathrm{O}_{4}$ during discharge/charge process. Hu et al. [16] have reported that porous cobalt oxide nanofibers coated with reduced graphene oxide (rGO) by hydrothermal reaction showed good rate capability as well as enhanced cyclic stability for a half cell and possessed high stable capacity with operation potential $(2 \mathrm{~V})$ for a full cell (the cathode electrode $\left(\mathrm{LiMn}_{2} \mathrm{O}_{4}\right)$ assembled with the anode electrode $\left(\mathrm{Co}_{3} \mathrm{O}_{4} @ \mathrm{rGO}\right)$ ).

The main aim of this research was to improve the characteristics of anode materials of lithium-ion batteries through depositing cobalt on carbon nanotubes/graphene composites by sputtering with different power levels as well as time periods and transforming cobalt into cobalt oxide by annealing.

\section{Materials and Methods}

Nickel foam with three-dimensional conductive network structure working as template for the growth of graphene 


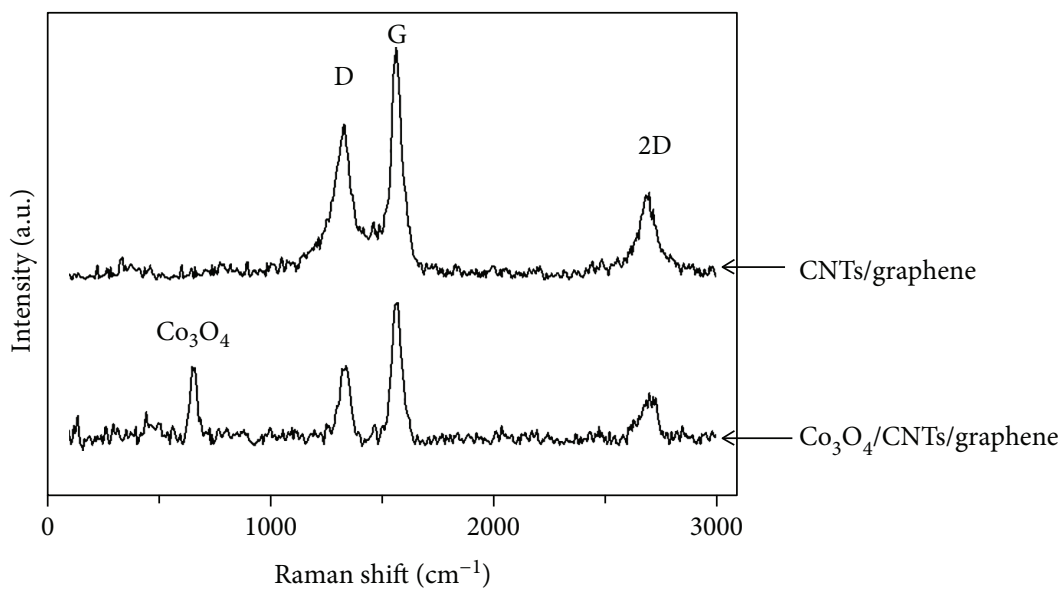

FIGURE 3: Raman spectra of carbon nanotubes/graphene composites and cobalt oxide/carbon nanotubes/graphene composites.

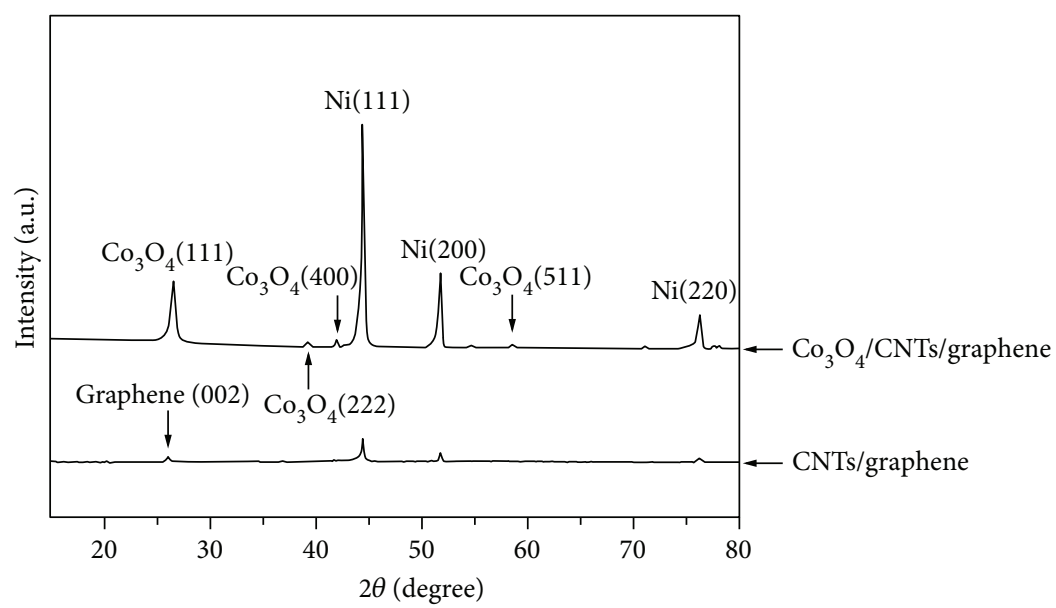

FIGURE 4: X-ray diffraction patterns of carbon nanotubes/graphene composites and cobalt oxide/carbon nanotubes/graphene composites (power $=100 \mathrm{~W}$ and time $=60 \mathrm{~min}$ for sputtering cobalt on carbon nanotubes/graphene composites).

facilitated easy access of electrolyte ions to the electrode surface $[17,18]$. The use of $\mathrm{Ni}$ foam is known to increase the active material utilization of the electrode, and thus, the specific capacitance of the electrode with the Ni foam current collector was higher than that with the $\mathrm{Ti}$ mesh current collector [17, 18]. The nickel foam $\left(1 \times 2 \times 0.1 \mathrm{~cm}^{3}\right)$ was degreased ultrasonically $(40 \mathrm{kHz})$ in acetone for $15 \mathrm{~min}$. Next, it was rinsed ultrasonically $(40 \mathrm{kHz})$ with pure deionized water for $15 \mathrm{~min}$ and then ovendried in air $\left(50^{\circ} \mathrm{C}\right)$ to constant weight.

First, the pretreated nickel foam substrate was heated at $1000^{\circ} \mathrm{C}$ in $\mathrm{H}_{2}(100 \mathrm{sccm})$ and $\mathrm{Ar}(250 \mathrm{sccm})$ for $10 \mathrm{~min}$ to reduce the surface oxide layer. Next, carbon nanotubes/ graphene composites were directly and simultaneously synthesized on the annealed nickel foam without additional catalysts using one-step ambient pressure thermal CVD with a gas mixture of $\mathrm{C}_{2} \mathrm{H}_{2}(15 \mathrm{sccm}), \mathrm{H}_{2}(100 \mathrm{sccm})$, and $\mathrm{Ar}$ $(250 \mathrm{sccm})$ for $10 \mathrm{~min}$ at $800^{\circ} \mathrm{C}$ and then cooled to ambient temperatures in Ar with the same volume flow rate as carbon nanotubes/graphene composites grown. Finally, the carbon nanotubes/graphene composites were weighed.

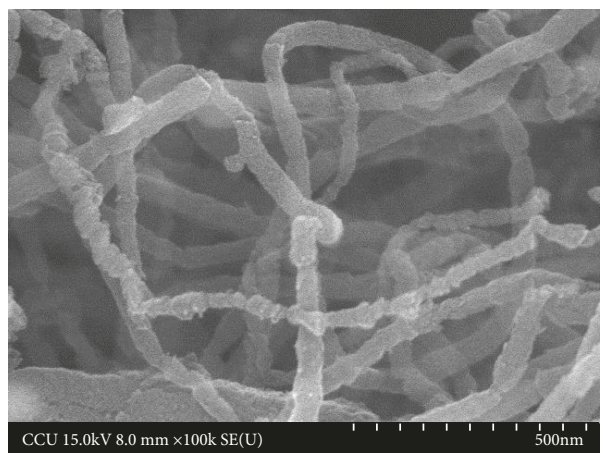

FIgURE 5: The FESEM images of carbon nanotubes/graphene composites.

The cobalt was deposited on the carbon nanotubes/ graphene composites by RF magnetron sputtering from a 3-inch disk Co target (purity: 99.9\%, purchased from SCM, INC) in a vacuum chamber with a background 


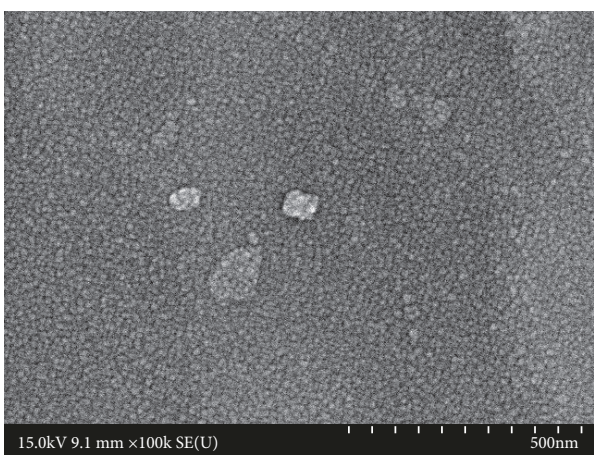

(a)

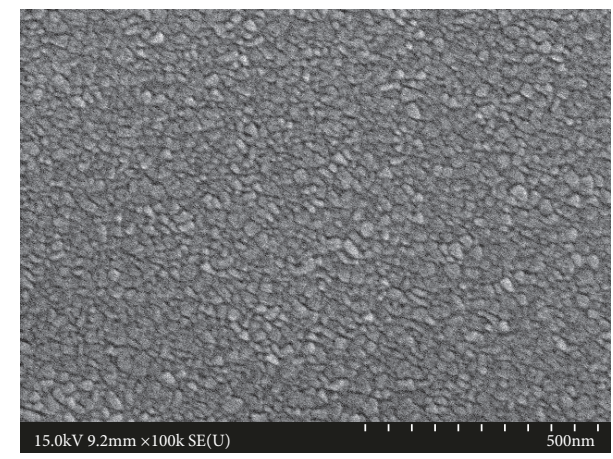

(b)

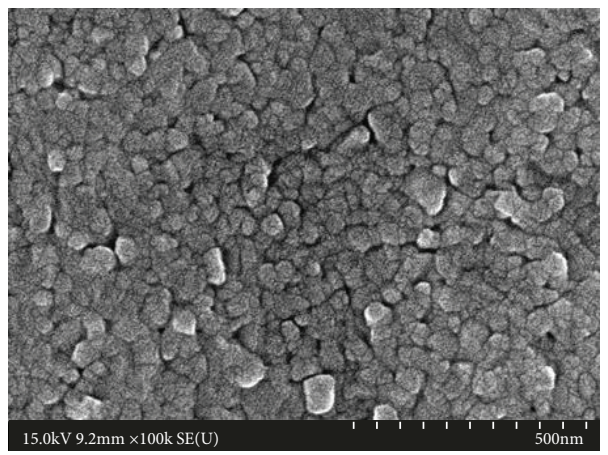

(c)

FIGURE 6: The FESEM images of cobalt oxide/carbon nanotubes/graphene composites with time period (60 min) and different power levels (a) $50 \mathrm{~W}$, (b) $100 \mathrm{~W}$, and (c) $150 \mathrm{~W}$ for sputtering cobalt onto carbon nanotube/graphene composite.

pressure of $7 \times 10^{-6}$ torr. The distance between the target and the substrate was $10 \mathrm{~cm}$. The pressure and volume flow rate of argon were maintained at $5 \mathrm{mtorr}$ and $15 \mathrm{sccm}$, respectively. The power levels $(50,100$, and $150 \mathrm{~W})$ and time levels $(30,45$, and $60 \mathrm{~min})$ were varied. Then, the cobalt was transformed into cobalt oxide by annealing at $250^{\circ} \mathrm{C}$ in air for $1 \mathrm{~h}$.

A solution of $1 \mathrm{M} \mathrm{LiPF}_{6}$ dissolved in $1: 1: 1(v / v)$ ethylene carbonate (EC)-ethyl methyl carbonate (EMC)-dimethyl carbonate (DMC) from Ubiq Technology was used as the electrolyte. The anode electrode (Li metal: 99.9\%, $0.3 \mathrm{~mm}$ thick, Ubiq Technology) was assembled with the cathode electrode (cobalt oxide or cobalt oxide/carbon nanotubes/ graphene composites) into a coin cell battery by using a coin cell manual crimping machine (CR2032, Taiwan) in an Arfilled glovebox. The electrochemical cycling tests were performed at 0.1-2 C using a cycler (PFX 2011, Kikusui, Japan).

The Co $2 \mathrm{p}$ peaks of $\mathrm{Co}_{3} \mathrm{O}_{4}$ for the $\mathrm{Co}_{3} \mathrm{O}_{4}$ /carbon nanotubes/graphene composites were explored by XPS (Fison VG. ESCA210, England). The D peak, G peak, 2D peak, and $\mathrm{Co}_{3} \mathrm{O}_{4}$ peak for the carbon nanotubes/graphene composites and $\mathrm{Co}_{3} \mathrm{O}_{4}$ /carbon nanotubes/graphene composites were investigated by microscopic Raman spectrometer (inVia, Renishaw, England). XRD (D8 Discover Bruker, Germany) with low angle of incidence was used to characterize the crystalline structure of carbon nanotubes/graphene composites and cobalt oxide/carbon nanotubes/graphene composites (power $=100 \mathrm{~W}$ and time $=60 \mathrm{~min}$ for sputtering cobalt on carbon nanotubes/graphene composites). Furthermore, the structure or the chemical composition of carbon nanotubes/graphene composites and cobalt oxide/carbon nanotubes/graphene composites for cobalt being sputtered onto carbon nanotubes/graphene composites at different power levels was conducted by field emission scanning electron microscope (FESEM) combined with energy-dispersive X-ray (EDX) (JEOL JSM-6700F, Japan). Additional information on the surface roughness (root mean square (rms) got by running NanoScope Analysis using original AFM data as input) of cobalt oxide/carbon nanotubes/graphene composites for cobalt being sputtered onto carbon nanotubes/ graphene composites at different power levels and time periods was obtained by atomic force microscope (Dimension Icon, Bruker, USA). Moreover, impedance measurement was performed using an electrochemical analyzer (CH Instruments $\mathrm{CHI} 608 \mathrm{~B}$, USA) at $5 \mathrm{mV} \mathrm{AC} \mathrm{amplitude}$ with a frequency range between $100 \mathrm{kHz}$ and $0.01 \mathrm{~Hz}$ to measure the charge-transfer resistance for cobalt oxide (power $=100 \mathrm{~W}$ and time $=60 \mathrm{~min}$ for sputtering cobalt on nickel foam) and cobalt oxide/carbon nanotubes/graphene composites (power $=100 \mathrm{~W}$ and time $=60 \mathrm{~min}$ for sputtering cobalt on carbon nanotubes/graphene composites). Cyclic voltammetry tests for cobalt oxide (power $=100 \mathrm{~W}$ and time $=60 \mathrm{~min}$ for sputtering cobalt on nickel foam), cobalt oxide/carbon nanotubes/graphene composites (power $=100 \mathrm{~W}$ and time $=60 \mathrm{~min}$ for sputtering cobalt on carbon nanotubes/graphene composites), and the lithiumion battery (full cell) for cobalt oxide/carbon nanotubes/ graphene composites (power $=100 \mathrm{~W}$ and time $=60 \mathrm{~min}$ for sputtering cobalt on carbon nanotubes/graphene composites) were performed using an electrochemical analyzer (CH Instruments CHI 608B, USA) at a scan rate of $0.1 \mathrm{mV} \mathrm{s}^{-1}$. 


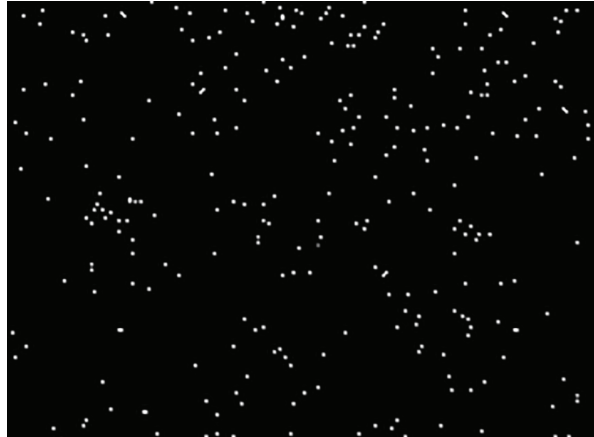

CKa1_2

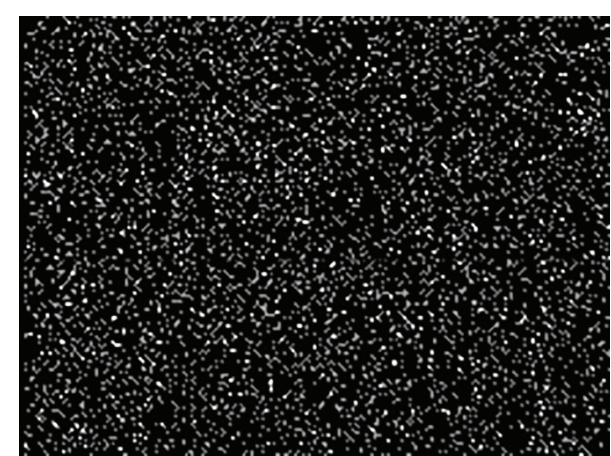

Co Kal

(a)

(b)

FIGURE 7: The EDX element distributions of (a) C and (b) Co in cobalt oxide/carbon nanotubes/graphene composites (power $=100 \mathrm{~W}$ and time $=60$ min for sputtering cobalt on carbon nanotubes/graphene composites).

\subsection{Results and Discussion. Figure 1 illustrates cobalt oxide} prepared by sputtering Co on CNTs/graphene grown on $\mathrm{Ni}$ foil by CVD and subsequent transformation of cobalt into cobalt oxide by annealing. The Co $2 \mathrm{p}$ XPS spectrum (Figure 2) of the $\mathrm{Co}_{3} \mathrm{O}_{4}$ /carbon nanotubes/graphene composites shows two peaks located at $780.5 \mathrm{eV}\left(\mathrm{Co} 2 \mathrm{p}_{3 / 2}\right)$ and $795.5 \mathrm{eV}\left(\mathrm{Co} 2 \mathrm{p}_{1 / 2}\right)$, and the spin-energy separation is $15 \mathrm{eV}$ with the characteristic of $\mathrm{Co}_{3} \mathrm{O}_{4}[5,8]$, which demonstrate the existence of $\mathrm{Co}_{3} \mathrm{O}_{4}$ in the composites. Furthermore, the Raman spectra (Figure 3 ) for the carbon nanotubes/graphene composites and $\mathrm{Co}_{3} \mathrm{O}_{4} /$ carbon nanotubes/graphene composites have three same peaks positioned at $1355 \mathrm{~cm}^{-1}$ (D), $1583 \mathrm{~cm}^{-1}(\mathrm{G})$, and $2679 \mathrm{~cm}^{-1}$ (2D) which can be assigned to carbon nanotubes and graphene; however, the additional peak at $667 \mathrm{~cm}^{-1}$ in the Raman spectrum for $\mathrm{Co}_{3} \mathrm{O}_{4} /$ carbon nanotubes/graphene composites can be attributed to $\mathrm{Co}_{3} \mathrm{O}_{4}$ which is in good agreement with the previous literatures $[5,8]$. Furthermore, X-ray diffraction patterns of carbon nanotubes/graphene composites and cobalt oxide/ carbon nanotubes/graphene composites (power $=100 \mathrm{~W}$ and time $=60 \mathrm{~min}$ for sputtering cobalt on carbon nanotubes/graphene composites) are shown in Figure 4. The peaks for CNTs/graphene in Figure 4 are identified as coming from the (111), (200), and (220) planes of facecentered cubic Ni metal (JCPDS card no. 04-0850) which originated from the $\mathrm{Ni}$ foam substrate. The peaks for $\mathrm{Co}_{3} \mathrm{O}_{4} / \mathrm{CNTs}$ /graphene in Figure 4 are the same as those for $\mathrm{CNTs}$ /graphene in Figure 4 except the peaks for $\mathrm{Co}_{3} \mathrm{O}_{4} / \mathrm{CNTs} /$ graphene in Figure 4 from the (111) diffraction plane of $\mathrm{Co}_{3} \mathrm{O}_{4}$ (JCPDS card no. 76-1802) [19], (222) and (400) crystal planes of $\mathrm{Co}_{3} \mathrm{O}_{4}$ (JCPDS card no. 73-1701) [20], and (511) plane of $\mathrm{Co}_{3} \mathrm{O}_{4}$ (JCPDS card no. 42-1467) [21]. Moreover, $\mathrm{Co}_{3} \mathrm{O}_{4}$ coated on CNTs/graphene was also confirmed by comparing the FESEM image in Figure 5 with the FESEM image in Figure 6(b) and from the EDX element distributions in Figure 7.

Figure 8 shows the effects of power levels and time periods for sputtering cobalt onto carbon nanotubes/graphene composites on the specific capacity $(0.1 \mathrm{C})$ of cobalt oxide/carbon nanotubes/graphene composites. It shows that the longer the time period of sputtering, the higher the specific capacity. The reason behind this may be that a longer

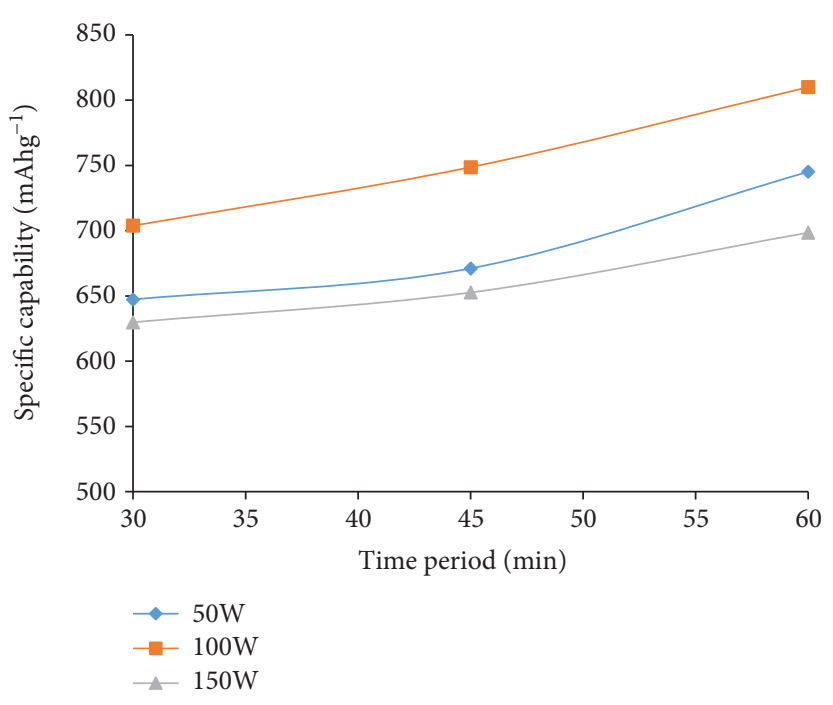

FIGURE 8: The effects of power levels and time periods for sputtering cobalt onto carbon nanotubes/graphene composites on the specific capacity $(0.1 \quad \mathrm{C})$ of cobalt oxide/carbon nanotubes/graphene composites.

time period of sputtering led to higher surface roughness (Figures 9 and 10), thus leading to higher specific capacity since a highly rough surface should possess large surface area [22]. Furthermore, the specific capacity increased at power levels in the range $50-100 \mathrm{~W}$. This picture may be explained as follows. The higher the power level, the higher the sputtering yield, thus enhancing the deposition rate. Then, particles falling on the carbon nanotubes/graphene composite surface do not have enough time to rearrange and resputter themselves; thus, more uniform particles are homogenously deposited (Figures 6(a) and 6(b)), which leads to increasing surface roughness (Figures 9 and 10) and specific capacity (Figure 8). However, the specific capacity decreased with power levels in the range $100-150 \mathrm{~W}$. This illustrates that an overly high power level leads to an overly strong ion and reflected neutral bombardment of the carbon nanotubes/ graphene composite surface, which only causes more damages and then increases the pore size (Figures 6(b) and 6(c)) and 


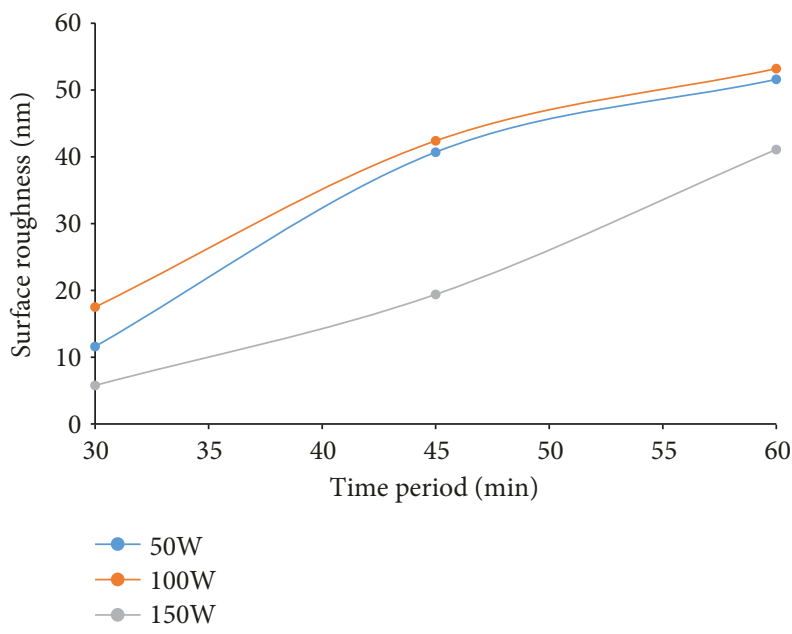

FIGURE 9: The effects of power levels and time periods for sputtering cobalt onto carbon nanotubes/graphene composites on the surface roughness of cobalt oxide/carbon nanotubes/graphene composites.

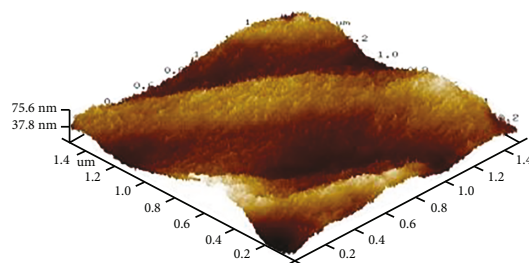

(a) $\mathrm{rms}=11.6 \mathrm{~nm}$

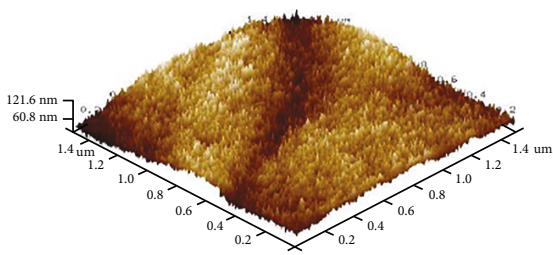

(d) $\mathrm{rms}=17.5 \mathrm{~nm}$

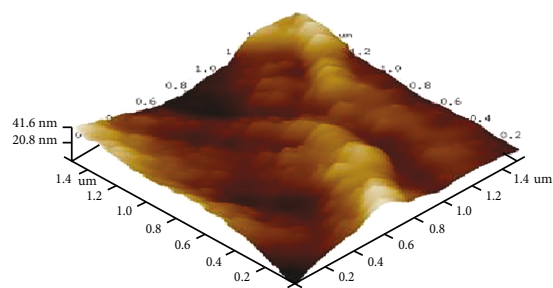

(g) $\mathrm{rms}=5.77 \mathrm{~nm}$

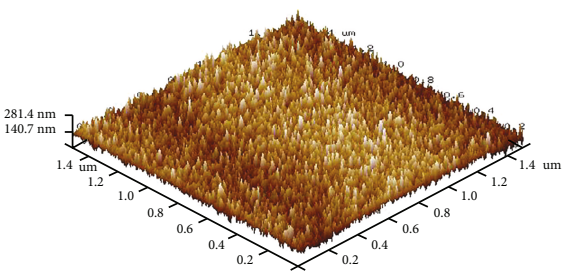

(b) $\mathrm{rms}=40.7 \mathrm{~nm}$

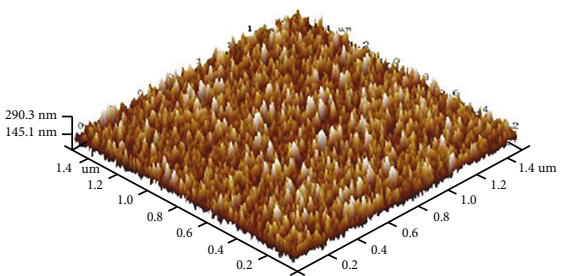

(e) $\mathrm{rms}=42.4 \mathrm{~nm}$

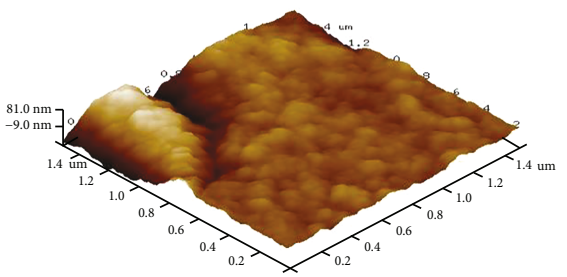

(h) $\mathrm{rms}=19.4 \mathrm{~nm}$

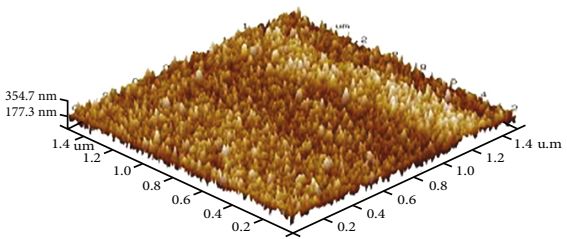

(c) $\mathrm{rms}=51.6 \mathrm{~nm}$

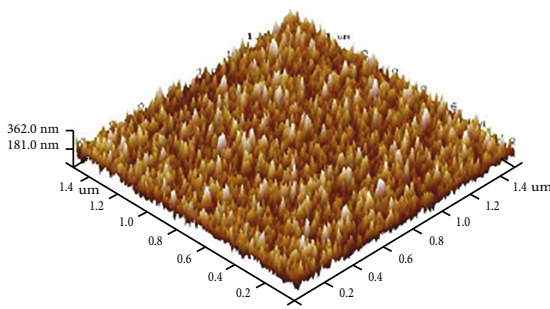

(f) $\mathrm{rms}=53.2 \mathrm{~nm}$

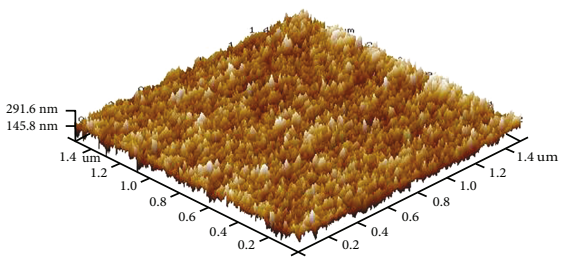

(i) $\mathrm{rms}=41.1 \mathrm{~nm}$

FIGURE 10: AFM micrograph of cobalt oxide/carbon nanotubes/graphene composites with different power levels and time periods (a) $50 \mathrm{~W}$ and $30 \mathrm{~min},(\mathrm{~b}) 50 \mathrm{~W}$ and $45 \mathrm{~min}$, (c) $50 \mathrm{~W}$ and $60 \mathrm{~min},(\mathrm{~d}) 100 \mathrm{~W}$ and $30 \mathrm{~min}$, (e) $100 \mathrm{~W}$ and $45 \mathrm{~min}$ (f) $100 \mathrm{~W}$ and $60 \mathrm{~min}$, (g) $150 \mathrm{~W}$ and $30 \mathrm{~min}$, (h) $150 \mathrm{~W}$ and $45 \mathrm{~min}$, and (i) $150 \mathrm{~W}$ and $60 \mathrm{~min}$ for sputtering cobalt onto carbon nanotube/graphene composite.

thus decreases surface roughness (Figures 9 and 10) as well as specific capacity (Figure 8).

The discharge/charge profiles $(0.1 \mathrm{C})$ of cobalt oxide (power $=100 \mathrm{~W}$ and time $=60 \mathrm{~min}$ for sputtering cobalt on nickel foam) and cobalt oxide/carbon nanotubes/graphene composites (power $=100 \mathrm{~W}$ and time $=60 \mathrm{~min}$ for sputtering cobalt on carbon nanotubes/graphene composites) are shown in Figures 11(a) and 11(b). The potential plateau in the first discharge curves of cobalt oxide/carbon nanotubes/ graphene composites is not more obvious than that of cobalt oxide since the crystallinity of cobalt oxide decreases by adding the poorly crystal carbon nanotubes/ graphene composites and a cathode peak (about $0.6 \mathrm{~V}$ ) in the first cycle of cobalt oxide is sharper than a cathode peak (about $0.7 \mathrm{~V}$ ) in the first cycle of cobalt oxide/carbon nanotubes/graphene composites (Figures 12(a) and 12(b)). 


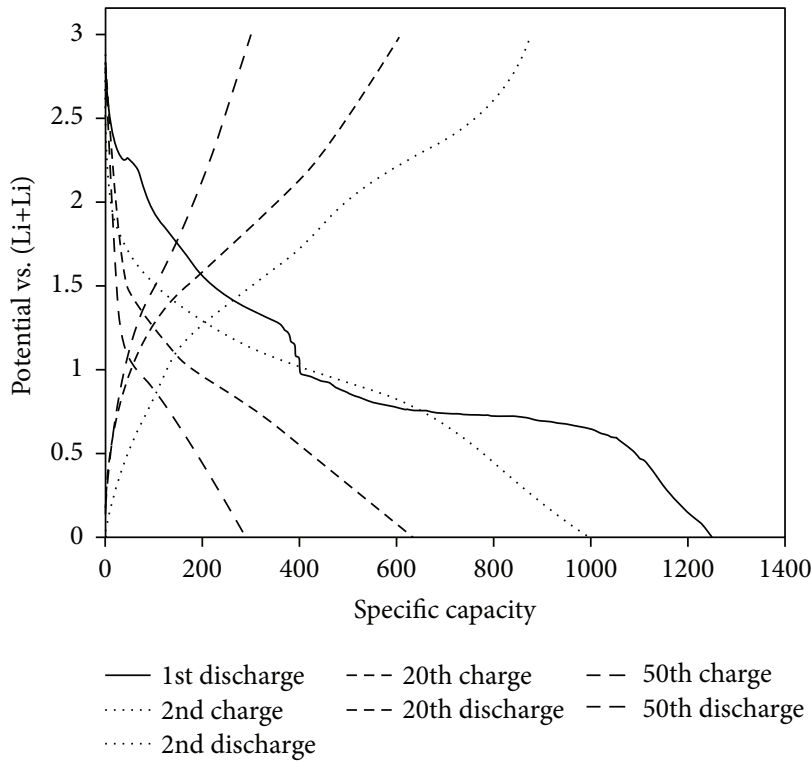

(a)

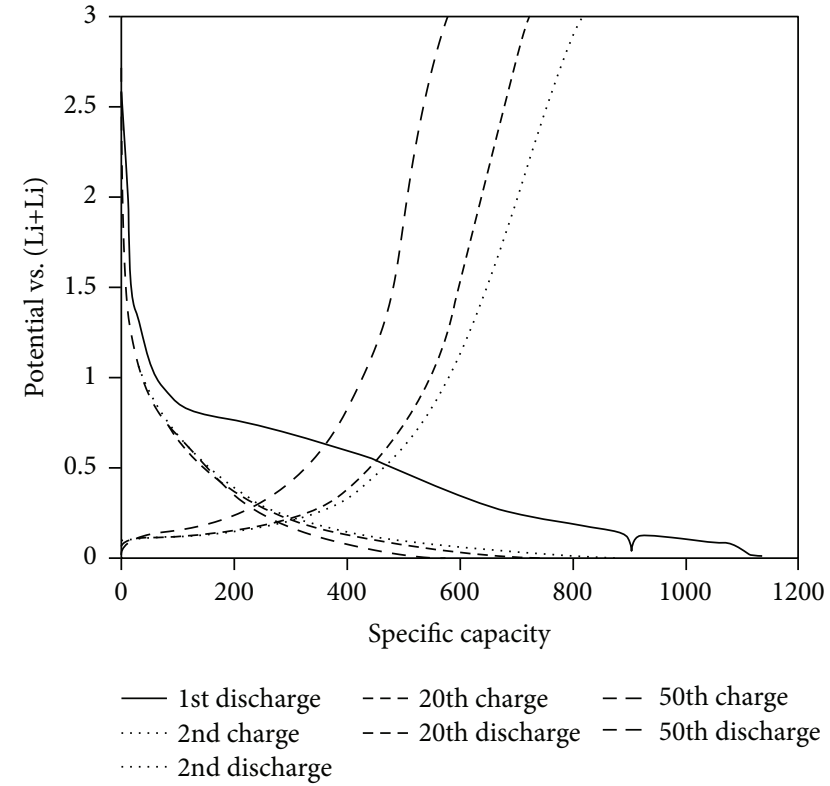

(b)

FIgURe 11: The discharge/charge profiles (between $0.01 \mathrm{~V}$ and $3 \mathrm{~V}$ at $0.1 \mathrm{C}$ ) of (a) cobalt oxide (power $=100 \mathrm{~W}$ and time $=60 \mathrm{~min}$ for sputtering cobalt on nickel foam) and (b) cobalt oxide/carbon nanotubes/graphene composites (power $=100 \mathrm{~W}$ and time $=60 \mathrm{~min}$ for sputtering cobalt on carbon nanotubes/graphene composites).

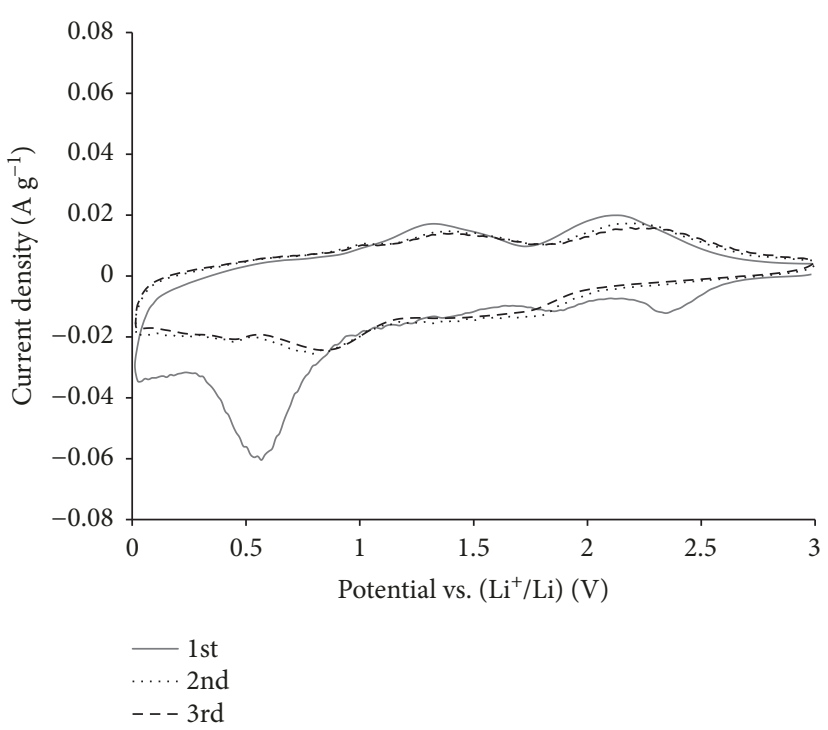

(a)

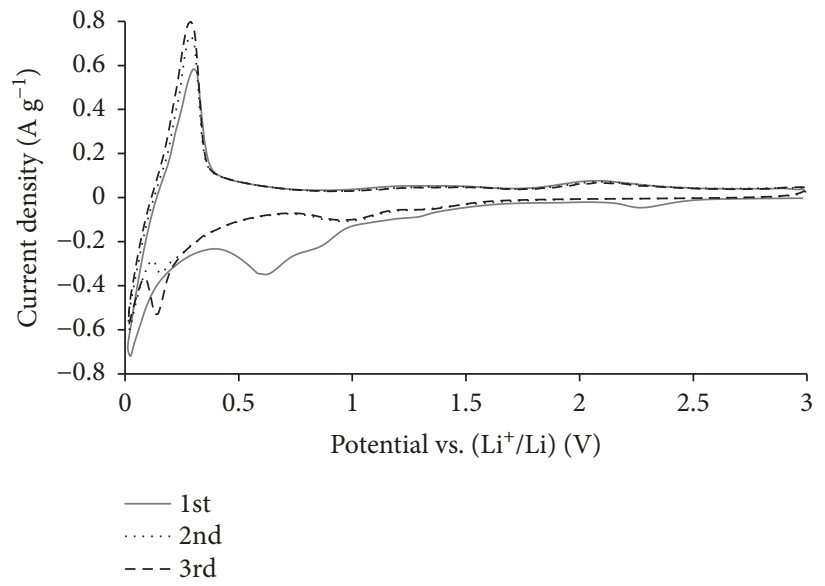

(b)

FIGURE 12: Cyclic voltammograms (between $0.01 \mathrm{~V}$ and $3 \mathrm{~V}$ from the 1 st cycle to the $3 \mathrm{rd}$ cycle) of (a) cobalt oxide (power $=100 \mathrm{~W}$ and time $=60 \mathrm{~min}$ for sputtering cobalt on nickel foam) and (b) cobalt oxide/carbon nanotubes/graphene composites (power $=100 \mathrm{~W}$ and time $=60 \mathrm{~min}$ for sputtering cobalt on carbon nanotubes/graphene composites).

The presence of the plateaus in the first discharge curve can be attributed to the formation of a solid electrolyte interface (SEI) film on the surface of electrodes [23] and the discharge plateaus disappear in the subsequent cycles (Figures 11(a) and 11(b)) which also is confirmed by the cathode peaks (about $0.6 \mathrm{~V}-0.7 \mathrm{~V}$ ) occurring during the first discharge scan and disappearing in the following cycles (Figures 12(a) and 12(b)). Furthermore, if discharge specific capacity $\left(200 \mathrm{mAhg}^{-1}\right)$ at the 2 nd cycle is the same, it occurs at higher potential (about $1.3 \mathrm{~V}$ ) for cobalt oxide and at lower potential (about $0.4 \mathrm{~V}$ ) for cobalt oxide/ carbon nanotubes/graphene composites (Figures 11(a) and $11(b))$. Moreover, if charge specific capacity $\left(400 \mathrm{mAh} \mathrm{g}^{-1}\right)$ at the 2 nd cycle is the same, it occurs at higher potential (about $1.5 \mathrm{~V}$ ) for cobalt oxide and at lower potential (about $0.4 \mathrm{~V}$ ) for cobalt oxide/carbon nanotubes/graphene composites (Figures 11(a) and 11(b)). Therefore, the cathode electrode $\left(\mathrm{LiCoO}_{2}\right)$ was assembled with the anode electrode 


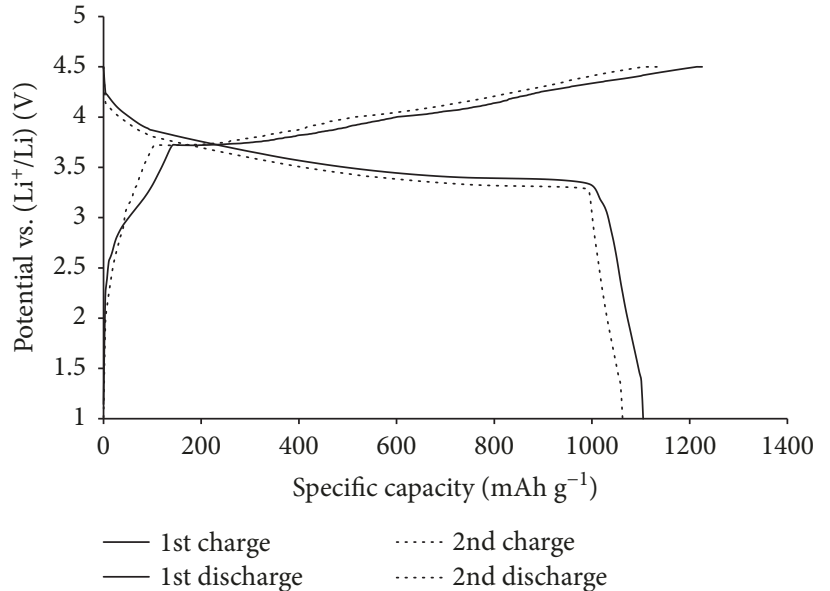

(a)

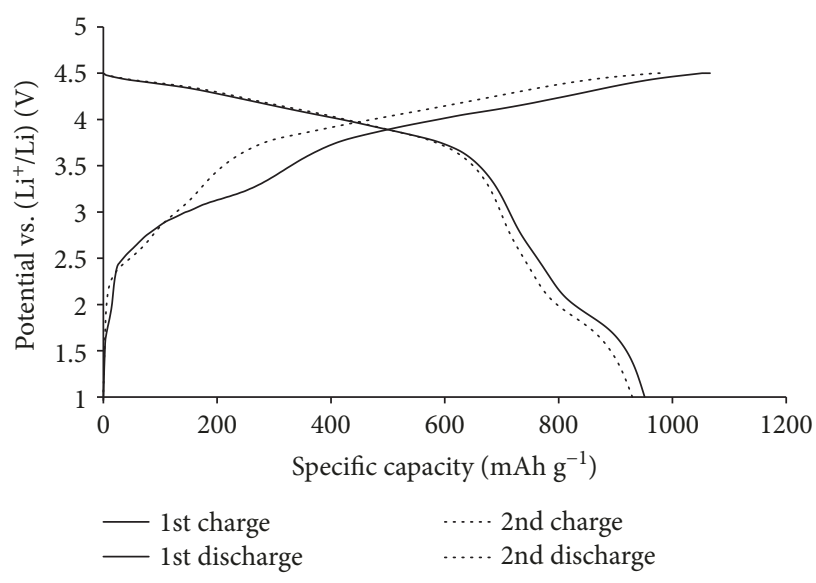

(b)

FIgure 13: The discharge/charge profiles (between $1 \mathrm{~V}$ and $4.5 \mathrm{~V}$ at $0.1 \mathrm{C}$ ) of the lithium-ion battery (full cell) for (a) cobalt oxide (power $=100 \mathrm{~W}$ and time $=60 \mathrm{~min}$ for sputtering cobalt on nickel foam) and (b) cobalt oxide/carbon nanotubes/graphene composites (power $=100 \mathrm{~W}$ and time $=60 \mathrm{~min}$ for sputtering cobalt on carbon nanotubes/graphene composites).

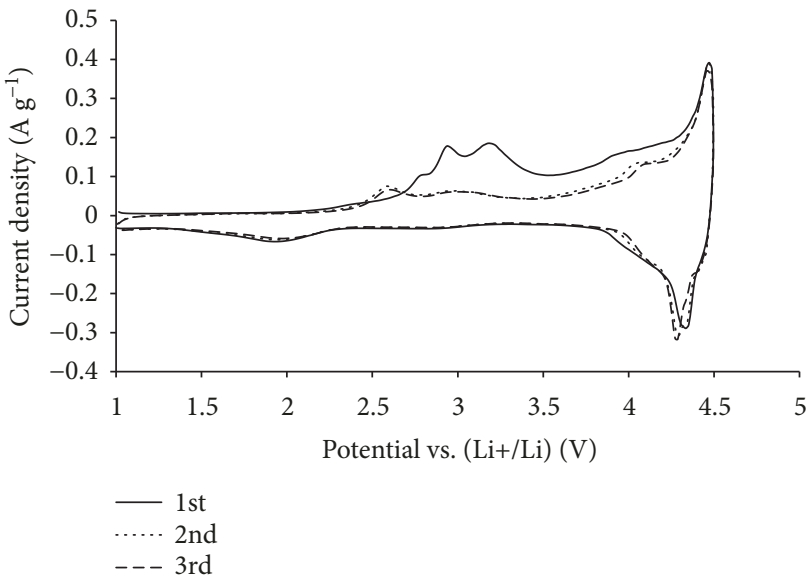

Figure 14: Cyclic voltammograms (between $1 \mathrm{~V}$ and $4.5 \mathrm{~V}$ from the 1st cycle to the 3rd cycle) of the lithium-ion battery (full cell) for cobalt oxide/carbon nanotubes/graphene composites (power $=100 \mathrm{~W}$ and time $=60 \mathrm{~min}$ for sputtering cobalt on carbon nanotubes/graphene composites).

$\left(\mathrm{Co}_{3} \mathrm{O}_{4}\right.$ or $\mathrm{Co}_{3} \mathrm{O}_{4}$ /carbon nanotubes/graphene composites) into a lithium-ion battery (full cell) and the potential plateau (about $3.5-4.5 \mathrm{~V}$ ) in the discharge curves $(0.1 \mathrm{C})$ of the lithium-ion battery (full cell) for cobalt oxide/carbon nanotubes/graphene composites is not more obvious than that (about 3.25-4.25 V) for cobalt oxide since the crystallinity of cobalt oxide decreases by adding the poorly crystal carbon nanotubes/graphene composites; however, the discharge processes of the lithium-ion battery (full cell) for cobalt oxide/carbon nanotubes/graphene composites occur at higher voltage (Figures 13(a) and 13(b)) for the benefit of merchantable lithium-ion batteries. Finally, the cyclic voltammograms of the lithium-ion battery (full cell) for cobalt oxide/carbon nanotubes/graphene composites are shown in Figure 14. The peaks were seen ranging from $2.9 \mathrm{~V}$ to $3.2 \mathrm{~V}$ (Figure 14) which can be attributed to the lithiation of

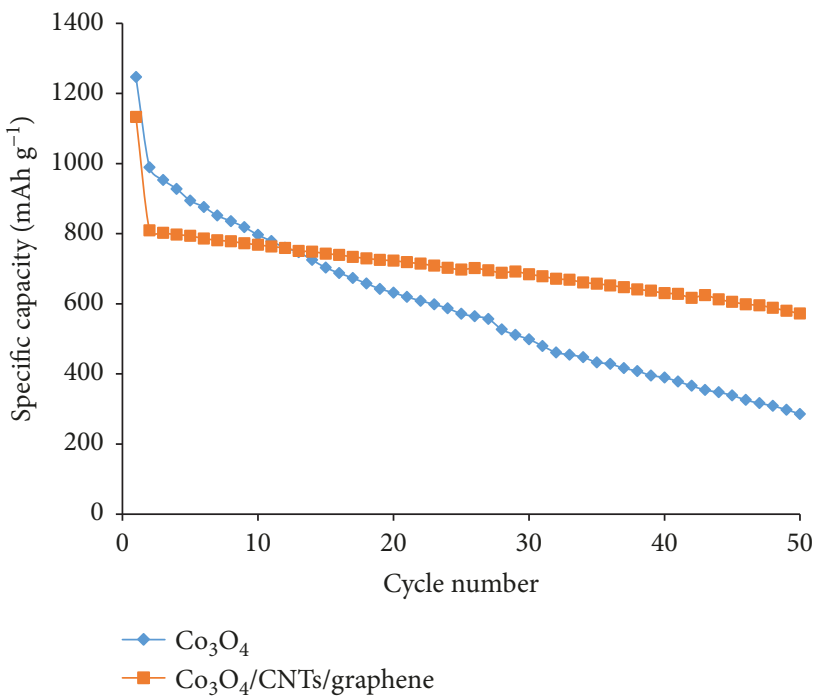

FIgURe 15: The effects of cobalt oxide (power $=100 \mathrm{~W}$ and time $=60 \mathrm{~min}$ for sputtering cobalt on nickel foam), cobalt oxide/ carbon nanotubes/graphene composites (power $=100 \mathrm{~W}$ and time $=60 \mathrm{~min}$ for sputtering cobalt on carbon nanotubes/graphene composites), and different charge/discharge cycles on the specific capacity $(0.1 \mathrm{C})$.

$\mathrm{Co}_{3} \mathrm{O}_{4}$ as well as delithiation of $\mathrm{LiCoO}_{2}$ during the charge processes, and the peak was observed at about $2 \mathrm{~V}$ (Figure 14) which can arise from the lithiation of $\mathrm{Li}_{1-\mathrm{x}} \mathrm{CoO}_{2}$ as well as delithiation of $\mathrm{Co} / \mathrm{Li}_{2} \mathrm{O}$ during the discharge processes $[16,24]$. The charge/discharge reactions of $\mathrm{Co}_{3} \mathrm{O}_{4}$, carbon nanotubes/graphene composites, and $\mathrm{LiCoO}_{2}$ can be described by 1,2 , and 3 , respectively $[5,25,26]$.

$$
\begin{gathered}
\mathrm{Co}_{3} \mathrm{O}_{4}+8 \mathrm{Li}^{+}+8 \mathrm{e}^{-} \leftrightarrow 3 \mathrm{Co}+4 \mathrm{Li}_{2} \mathrm{O} \\
6 \mathrm{C}+\mathrm{xLi}^{+}+\mathrm{xe}^{-} \leftrightarrow \mathrm{C}_{6} \mathrm{Li}_{\mathrm{x}}
\end{gathered}
$$




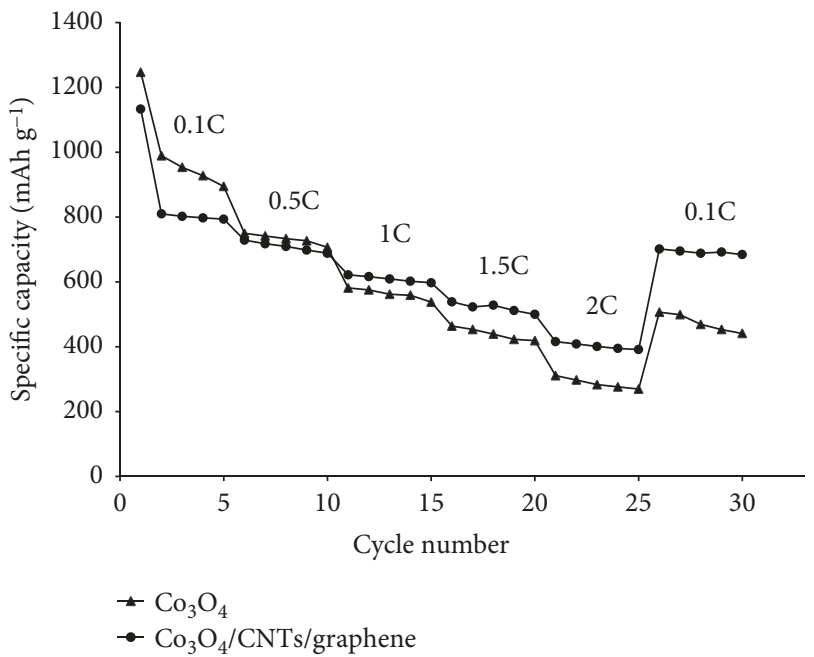

Figure 16: Rate capability (between $0.01 \mathrm{~V}$ and $3 \mathrm{~V}$ ) for the cobalt oxide (power $=100 \mathrm{~W}$ and time $=60$ min for sputtering cobalt on nickel foam) and cobalt oxide/carbon nanotubes/graphene composites (power $=100 \mathrm{~W}$ and time $=60 \mathrm{~min}$ for sputtering cobalt on carbon nanotubes/graphene composites).

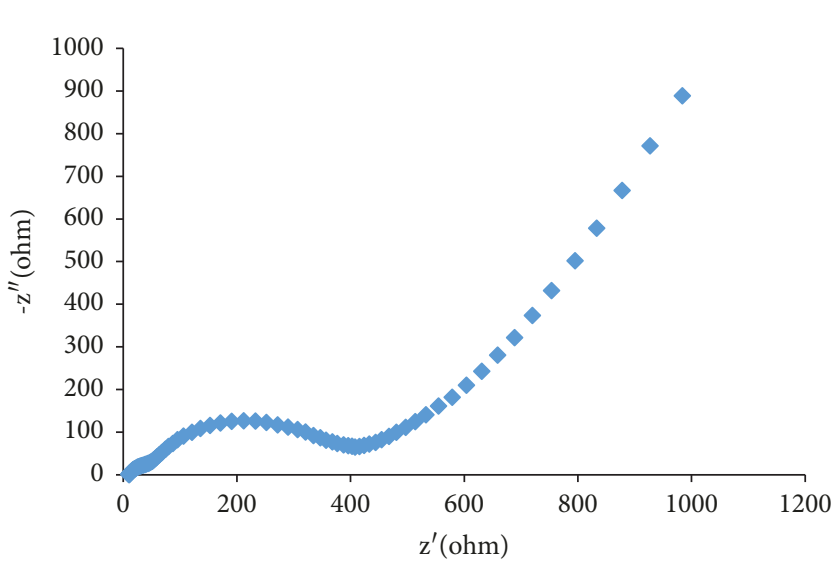

(a)

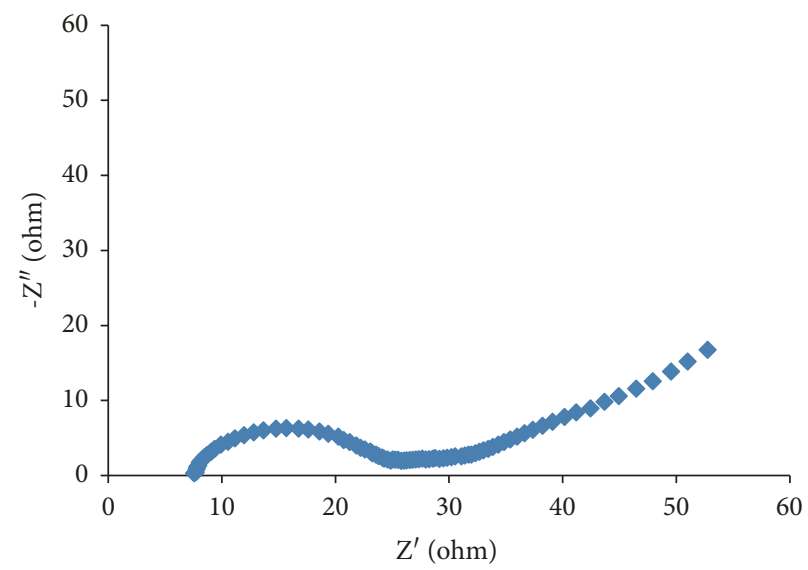

(b)

FIGURE 17: Nyquist diagrams of (a) cobalt oxide (power $=100 \mathrm{~W}$ and time $=60 \mathrm{~min}$ for sputtering cobalt on nickel foam) and (b) cobalt oxide/ carbon nanotubes/graphene composites (power $=100 \mathrm{~W}$ and time $=60 \mathrm{~min}$ for sputtering cobalt on carbon nanotubes/graphene composites).

$$
\mathrm{LiCoO}_{2} \leftrightarrow \mathrm{Li}_{1-\mathrm{x}} \mathrm{CoO}_{2}+\mathrm{xLi}^{+}+\mathrm{xe}^{-} \quad(0 \leqq x \leqq 1)
$$

Figure 15 shows the effects of cobalt oxide (power $=100 \mathrm{~W}$ and time $=60 \mathrm{~min}$ for sputtering cobalt on nickel foam), cobalt oxide/carbon nanotubes/graphene composites (power $=100 \mathrm{~W}$ and time $=60 \mathrm{~min}$ for sputtering cobalt on carbon nanotubes/graphene composites), and different charge/discharge cycles on the specific capacity $(0.1 \mathrm{C})$. The reason for the large specific capacity fading after the first cycle (Figure 15) could possibly be the irreversible lithium loss due to the side reaction of electrolyte decomposition and then formation of a SEI film [23]. Cobalt oxide/carbon nanotubes/graphene composites possessed a better cycling performance (specific capacity only decreased $29 \%$ from the 2 nd cycle to the 50 th cycle in Figure 15) in comparison to cobalt oxide (specific capacity decreased $71 \%$ from the 2 nd cycle to the 50th cycle in Figure 15) since the CNTs/G composites could provide stable support to cobalt oxide and allow volume expansion of cobalt oxide without the severe cracking or crumbling of electrode materials during discharge/charge cycles $[5,9,10]$, which also is confirmed by the discharge/charge profiles of cobalt oxide and cobalt oxide/carbon nanotubes/graphene composites (Figures 11(a) and 11(b)). The specific capacity for cobalt oxide/carbon nanotubes/graphene composites is about two-fold of the specific capacity for cobalt oxide after the 50th cycle (Figure 15). Furthermore, cobalt oxide/carbon nanotubes/graphene composites show better rate capability in comparison to cobalt oxide at different C-rates (Figures 16(a) and 16(b)) since the charge-transfer resistance $(16.7 \mathrm{ohm})$ for cobalt oxide/carbon nanotubes/ graphene composites is much lower than that (366.6 ohm) for cobalt oxide (Figures 17(a) and 17(b)), hinting that cobalt oxide/carbon nanotubes/graphene composites show faster charge transfer during the lithium-ion insertion/ extraction reaction. The cobalt oxide/carbon nanotubes/ 
graphene composites almost recover its original specific capacity while the C-rate is back to the initial $0.1 \mathrm{C}$ after 25 cycles; however, the cobalt oxide exhibits apparent specific capacity drop.

\section{Conclusions}

The Co 2p XPS spectrum shows the existence of $\mathrm{Co}_{3} \mathrm{O}_{4}$ in the composites, which also is confirmed by the Raman spectra. Furthermore, the specific capacity increased at power levels in the range 50-100 W; however, the specific capacity decreased with power levels in the range 100-150 W. Moreover, discharge processes of the lithium-ion battery (full cell) for cobalt oxide/carbon nanotubes/graphene composites occur at higher potential for the benefit of merchandising. Finally, cobalt oxide/carbon nanotubes/graphene composites exhibit better rate capability compared with cobalt oxide at different C-rates.

\section{Data Availability}

The data used to support the findings of this study are available from the corresponding author upon request.

\section{Disclosure}

Furthermore, the abstract entitled "Synthesis of cobaltic oxide/carbon nanotube/graphene composites for anode materials of lithium-ion batteries" was done in the oral presentation by Chuen-Chang Lin from National Yunlin University of Science and Technology, Taiwan, in the 20th International Conference on Emerging Materials and Nanotechnology during June 25-26, 2018, at Vancouver, British Columbia, Canada.

\section{Conflicts of Interest}

The authors declare that there is no conflict of interests regarding the publication of this paper.

\section{Acknowledgments}

Financial support by the Ministry of Science and Technology of the Republic of China (under grant no. MOST 106-2221E-224-042) is gratefully acknowledged.

\section{References}

[1] D. Miranda, C. M. Costa, and S. Lanceros-Mendez, "Lithium ion rechargeable batteries: state of the art and future needs of microscopic theoretical models and simulations," Journal of Electroanalytical Chemistry, vol. 739, pp. 97-110, 2015.

[2] W. Wang, I. Ruiz, S. Guo et al., "Hybrid carbon nanotube and graphene nanostructures for lithium ion battery anodes," Nano Energy, vol. 3, pp. 113-118, 2014.

[3] W. Wang, S. Guo, M. Penchev et al., "Three dimensional few layer graphene and carbon nanotube foam architectures for high fidelity supercapacitors," Nano Energy, vol. 2, no. 2, pp. 294-303, 2013.
[4] C. C. Lin and Y. W. Lin, "Synthesis of carbon nanotube/ graphene composites by one-step chemical vapor deposition for electrodes of electrochemical capacitors," Journal of Nanomaterials, vol. 2015, Article ID 741928, 8 pages, 2015.

[5] Y. Han, L. Dong, J. Feng, D. Li, X. Li, and S. Liu, "Cobalt oxide modified porous carbon anode enhancing electrochemical performance for Li-ion batteries," Electrochimica Acta, vol. 167, pp. 246-253, 2015.

[6] T. H. Yoon and Y. J. Park, "Electrochemical properties of CNTs $/ \mathrm{Co}_{3} \mathrm{O}_{4}$ blended anode for rechargeable lithium batteries," Solid State Ionics, vol. 225, pp. 498-501, 2012.

[7] S. M. Abbas, S. T. Hussain, S. Ali, N. Ahmad, N. Ali, and K. S. Munawar, "Synthesis of carbon nanotubes anchored with mesoporous $\mathrm{Co}_{3} \mathrm{O}_{4}$ nanoparticles as anode material for lithium-ion batteries," Electrochimica Acta, vol. 105, pp. 481488, 2013.

[8] B. Li, H. Cao, J. Shao, G. Li, M. Qu, and G. Yin, " $\mathrm{Co}_{3} \mathrm{O}_{4} @ g r a-$ phene composites as anode materials for high-performance lithium ion batteries," Inorganic Chemistry, vol. 50, no. 5, pp. 1628-1632, 2011.

[9] B. Wang, Y. Wang, J. Park, H. Ahn, and G. Wang, "In situ synthesis of $\mathrm{Co}_{3} \mathrm{O}_{4}$ /graphene nanocomposite material for lithiumion batteries and supercapacitors with high capacity and supercapacitance," Journal of Alloys and Compounds, vol. 509, no. 29, pp. 7778-7783, 2011.

[10] D. Qiu, G. Bu, B. Zhao et al., "In situ growth of mesoporous $\mathrm{Co}_{3} \mathrm{O}_{4}$ nanoparticles on graphene as a high-performance anode material for lithium-ion batteries," Materials Letters, vol. 119, pp. 12-15, 2014.

[11] Y. Lou, J. Liang, Y. Peng, and J. Chen, "Ultra-small $\mathrm{Co}_{3} \mathrm{O}_{4}$ nanoparticles-reduced graphene oxide nanocomposite as superior anodes for lithium-ion batteries," Physical Chemistry Chemical Physics, vol. 17, no. 14, pp. 8885-8893, 2015.

[12] X. Yang, K. Fan, Y. Zhu et al., "Electric papers of graphenecoated $\mathrm{Co}_{3} \mathrm{O}_{4}$ fibers for high-performance lithium-ion batteries," ACS Applied Materials \& Interfaces, vol. 5, no. 3, pp. 997-1002, 2013.

[13] Q. Yang, J. Wu, K. Huang et al., "Layer-by-layer self-assembly of graphene-like $\mathrm{Co}_{3} \mathrm{O}_{4}$ nanosheet/graphene hybrids: towards high-performance anode materials for lithium-ion batteries," Journal of Alloys and Compounds, vol. 667, pp. 29-35, 2016.

[14] Z. S. Wu, W. Ren, L. Wen et al., "Graphene anchored with $\mathrm{Co}_{3} \mathrm{O}_{4}$ nanoparticles as anode of lithium ion batteries with enhanced reversible capacity and cyclic performance," ACS Nano, vol. 4, no. 6, pp. 3187-3194, 2010.

[15] L. Li, G. Zhou, X. Y. Shan, S. Pei, F. Li, and H. M. Cheng, " $\mathrm{Co}_{3} \mathrm{O}_{4}$ mesoporous nanostructures@graphene membrane as an integrated anode for long-life lithium-ion batteries," Journal of Power Sources, vol. 255, pp. 52-58, 2014.

[16] R. Hu, H. Zhang, Y. Bu, H. Zhang, B. Zhao, and C. Yang, "Porous $\mathrm{Co}_{3} \mathrm{O}_{4}$ nanofibers surface-modified by reduced graphene oxide as a durable, high-rate anode for lithium ion battery," Electrochimica Acta, vol. 228, pp. 241-250, 2017.

[17] T. Xiao, X. Hu, B. Heng et al., " $\mathrm{Ni}(\mathrm{OH})_{2}$ nanosheets grown on graphene-coated nickel foam for high-performance pseudocapacitors," Journal of Alloys and Compounds, vol. 549, pp. 147151, 2013.

[18] Y. Wang, A. Yuan, and X. Wang, "Pseudocapacitive behaviors of nanostructured manganese dioxide/carbon nanotubes composite electrodes in mild aqueous electrolytes: effects of 
electrolytes and current collectors," Journal of Solid State Electrochemistry, vol. 12, no. 9, pp. 1101-1107, 2008.

[19] S. R. M. Rusi, "Electrodeposited $\mathrm{Mn}_{3} \mathrm{O}_{4}-\mathrm{NiO}-\mathrm{Co}_{3} \mathrm{O}_{4}$ as a composite electrode material for electrochemical capacitor," Electrochimica Acta, vol. 175, pp. 193-201, 2015.

[20] K. Jiao, Y. Jiang, Z. Kang, R. Peng, S. Jiao, and Z. Hu, “Threedimensional $\mathrm{Co}_{3} \mathrm{O}_{4} @ M W N T$ nanocomposite with enhanced electrochemical performance for nonenzymatic glucose biosensors and biofuel cells," Royal Society Open Science, vol. 4, no. 12, article 170991, 2017.

[21] W. Zhang, Y. Fu, and X. Wang, " $\mathrm{Co}_{3} \mathrm{O}_{4}$ nanocrystals with exposed low-surface-energy planes anchored on chemically integrated graphitic carbon nitride-modified nitrogen-doped graphene: a high-performance anode material for lithium-ion batteries," Applied Surface Science, vol. 439, pp. 447-455, 2018.

[22] C. C. Hu and T. W. Tsou, "The optimization of specific capacitance of amorphous manganese oxide for electrochemical supercapacitors using experimental strategies," Journal of Power Sources, vol. 115, no. 1, pp. 179-186, 2003.

[23] X. M. Liu, Z. D. Huang, S. W. Oh et al., "Carbon nanotube (CNT)-based composites as electrode material for rechargeable Li-ion batteries," Composites Science and Technology, vol. 72, no. 2, pp. 121-144, 2012.

[24] J. Wang, G. Wang, and H. Wang, "Flexible free-standing $\mathrm{Fe}_{2} \mathrm{O}_{3}$ /graphene/carbon nanotubes hybrid films as anode materials for high performance lithium-ion batteries," Electrochimica Acta, vol. 182, pp. 192-201, 2015.

[25] A. D. Roberts, X. Li, and H. Zhang, "Porous carbon spheres and monoliths: morphology control, pore size tuning and their applications as Li-ion battery anode materials," Chemical Society Reviews, vol. 43, no. 13, pp. 4341-4356, 2014.

[26] X. Li, F. Cheng, B. Guo, and J. Chen, "Template-synthesized $\mathrm{LiCoO}_{2}, \mathrm{LiMn}_{2} \mathrm{O}_{4}$, and $\mathrm{LiNi}_{0.8} \mathrm{Co}_{0.2} \mathrm{O}_{2}$ nanotubes as the cathode materials of lithium ion batteries," The Journal of Physical Chemistry B, vol. 109, no. 29, pp. 14017-14024, 2005. 


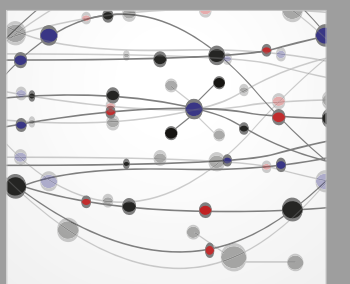

The Scientific World Journal
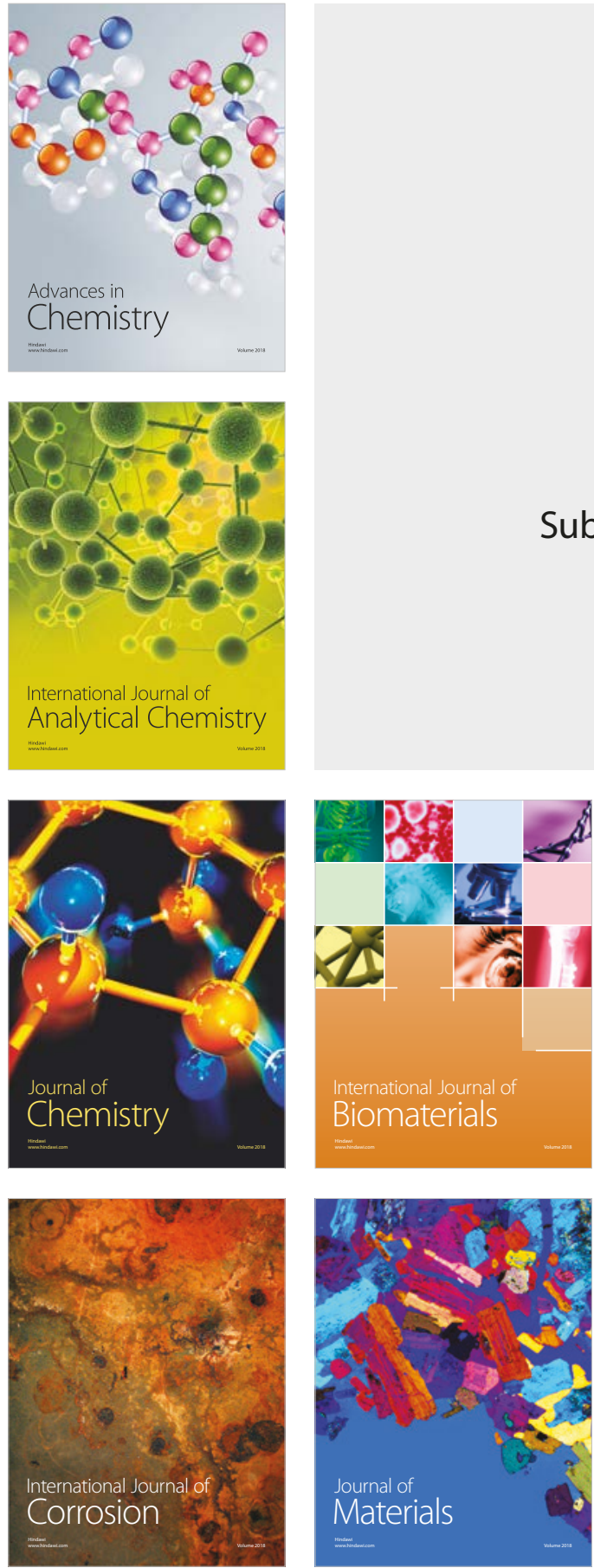

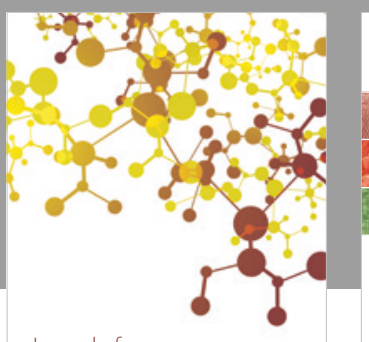

Journal of

Applied Chemistry
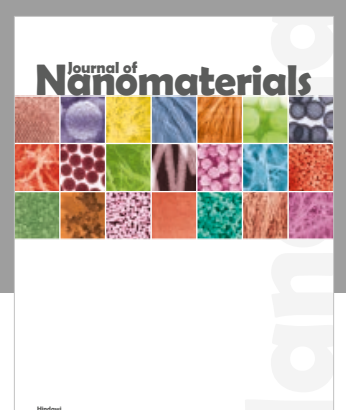

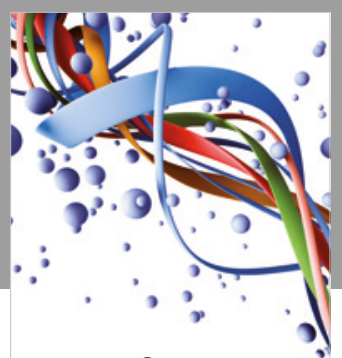

Scientifica

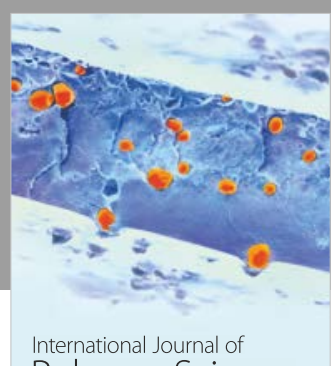

Polymer Science

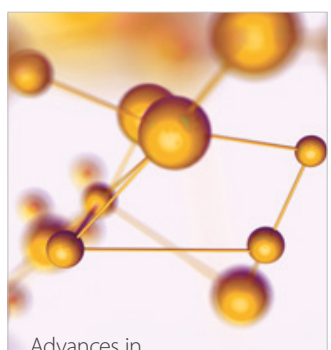

Physical Chemistry
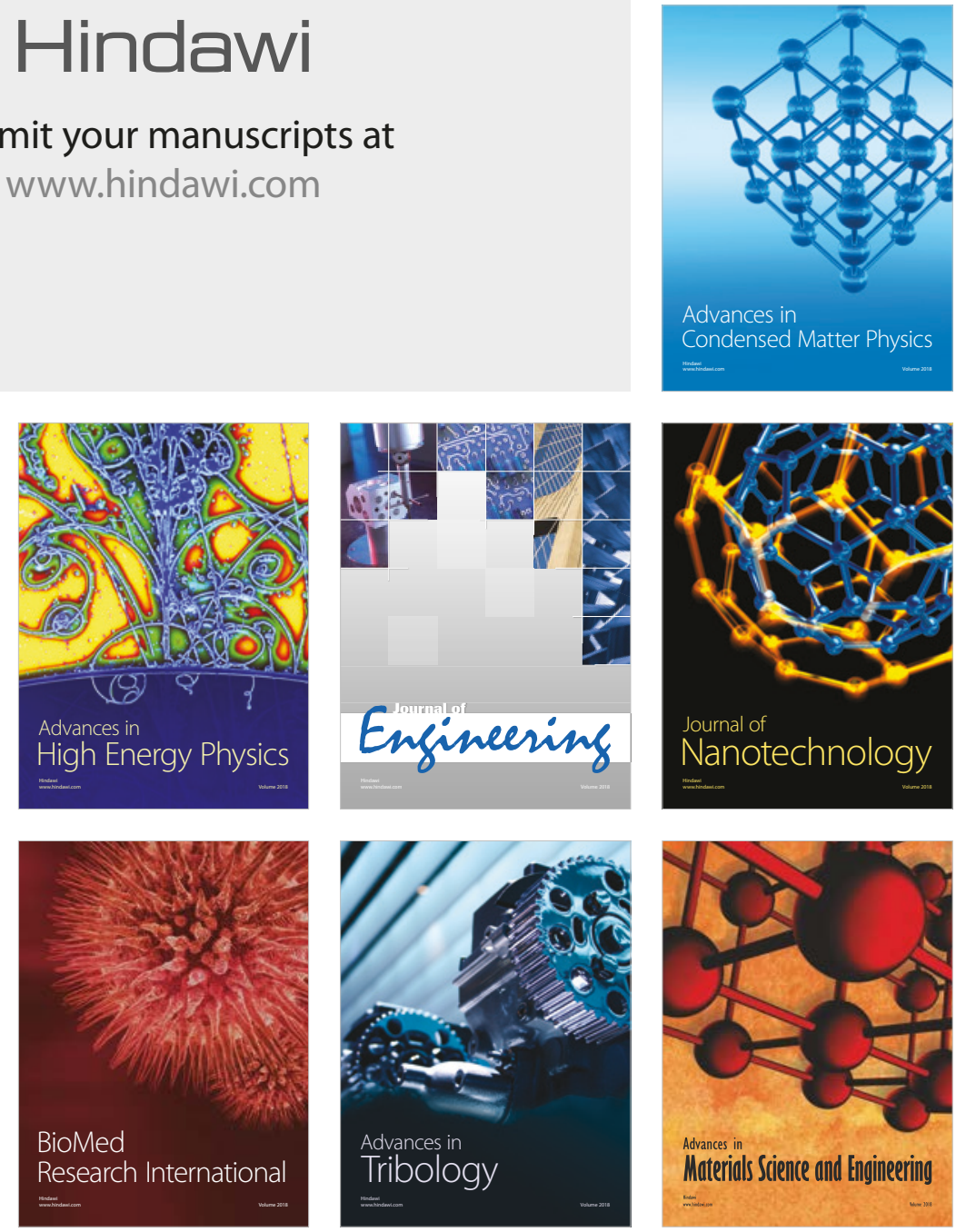